\title{
LOGÍSTICA REVERSA: UM ESTUDO EM SUPERMERCADOS DE CIDADES DO INTERIOR PAULISTA
}

Camila Brunassi de Araujo ${ }^{1}$

Marcela Machado Zambon ${ }^{2}$

Nayla Furlan da Silva ${ }^{3}$

Marçal Rogério Rizzo ${ }^{4}$

RESUMO: A crescente preocupação com o meio ambiente propõe que a sociedade, em suas várias dimensões, tenha maior consciência ambiental sobre os resíduos que são gerados diariamente. Resíduos sólidos têm sido um dos dilemas que a sociedade vivencia nos dias atuais. A partir disso, quais seriam possíveis soluções para amenizar o problema? A logística reversa (LR) é uma das ações que vem ao encontro da política dos "3Rs" (Reduzir, Reutilizar e Reciclar). Este artigo surgiu para identificar as dimensões nas quais a LR é colocada em prática no ramo de supermercados de cidades do interior paulista e, por sua vez, quais as vantagens obtidas com sua implementação. Para atingir o objetivo, inicialmente 0 meio de investigação utilizado foi a pesquisa bibliográfica $e$ documental, a partir de livros, artigos, revistas e jornais. Posteriormente, foram coletados dados e informações por meio de entrevistas junto a seis supermercados localizados nas cidades paulistas de São José do Rio Preto, Votuporanga e Castilho. O estudo demonstrou que a LR está presente em todos os supermercados, especialmente no que se refere às embalagens plásticas e de papelão. Já os resíduos provenientes de frutas, legumes e verduras (FLV), ou seja, produtos não vendáveis, têm tratamento diferenciado. Esse tratamento também é fruto do planejamento e das demandas que o ambiente

\footnotetext{
${ }^{1}$ Acadêmica do $2^{\circ}$ Ano do curso de Administração da Universidade Federal do Mato Grosso do SUL (UFMS) - Campus de Três Lagoas. Contato: camila_brunassi@hotmail.com

${ }^{2}$ Acadêmica do 2ํㅡㄹ Ano do curso de Administração da Universidade Federal do Mato Grosso do SUL (UFMS) - Campus de Três Lagoas. Contato: marcelamachadozambon@hotmail.com

${ }^{3}$ Acadêmica do 2ำ Ano do curso de Administração da Universidade Federal do Mato Grosso do SUL (UFMS) - Campus de Três Lagoas. Contato: naah.furlan@hotmail.com

${ }^{4}$ Graduado em Ciências Econômicas, mestre em Desenvolvimento Econômico (IE/UNICAMP), doutorando em Geografia na área de Dinâmica e Gestão Ambiental pela Universidade Estadual Paulista "Júlio de Mesquita Filho" (FCT/UNESP) - Campus de Presidente Prudente/SP - professor assistente da Universidade Federal do Mato Grosso do Sul (UFMS) - Campus de Três Lagoas e pesquisador do Núcleo de Estudos em Sustentabilidade, Desenvolvimento Local e Regional (NESDER). Contato: marcalprofessor@yahoo.com.br
} 
empresarial de cada supermercado provoca, surgindo para responder adequadamente a tal contexto.

Palavras-chave: Logística Reversa; Resíduos Sólidos; Lixo; Gestão Ambiental; Varejo.

\section{INTRODUÇÃO}

Durante muitos séculos, o meio ambiente foi visto apenas como uma fonte de matérias-primas para as atividades econômicas. Por trás desse pensamento, acreditavase que os recursos naturais eram inesgotáveis e que o crescimento econômico poderia continuar nas mesmas proporções sem preocupar-se com o estoque de recursos.

Ocorre, todavia, que, à medida que a sociedade evolui, os desafios impostos para o meio ambiente e a saúde pública também avançam e, na maioria das vezes, desproporcionalmente, como é o caso da geração e destinação do lixo que é gerado diariamente pela humanidade.

Os hábitos de consumo da sociedade atual sofreram significativas mudanças no que concerne à diversificação e ampliação do consumo de alimentos industrializados, gerando, assim, grande volume de embalagens descartadas, que especificamente, representam grande volume e problema ambiental sob vários aspectos.

Os supermercados (varejo), são parte dos canais de distribuição e o principal "elo" entre a indústria e o consumidor final. A partir da mencionada mudança nos hábitos de consumo, passaram a ter volumes maiores de resíduos, como embalagens plásticas, papel, papelão, entre outros. Qual destino dar para esses resíduos?

De acordo com Braga Júnior (2010), a LR no setor varejista pode abrir-se como uma nova possibilidade de ganho para as empresas do setor, pois passa a criar um fluxo reverso das sobras de embalagens e produtos que seriam descartados.

Nesse processo de retorno de mercadorias e materiais rejeitados, a LR pode contribuir para o desempenho da empresa ao possibilitar um aproveitamento do que foi gerado e seria descarte; um aproveitamento econômico. Além disso, a LR traz ganhos ambientais para toda a sociedade, pois o que antes iria avolumar-se em aterros sanitários e lixões a céu aberto agora ingressa no ciclo do reaproveitamento e da reciclagem. 


\title{
2. RESÍDUOS SÓLIDOS: UM GRAVE PROBLEMA NA ATUALIDADE
}

De acordo com Oliveira (2010), citando o pesquisador e professor Jacques Demajorovic, o termo "lixo" foi substituído por "resíduos sólidos" e estes que anteriormente eram entendidos como meros subprodutos do sistema produtivo, passaram a ser encarados como responsáveis por graves problemas de degradação ambiental.

Nesse contexto, resíduos sólidos são todos os restos das atividades humanas ou sobras de alimentos, embalagens, plásticos e outros. É tudo o que é considerado como indesejável, descartável ou ate mesmo inútil.

Por sua vez, o dicionário de língua portuguesa Aurélio apresenta a seguinte definição para resíduo: "[...] o que resta de qualquer substância; resto". Já lixo é o que se "[...] varre da casa, da rua, e se joga fora; entulho. [...] coisa imprestável".

Ainda no campo das definições, Tenório; Espinosa (2004, p.158) conceituam "resíduos sólidos" como:

\begin{abstract}
Resíduos nos estados sólido e semi-sólido, que resultam de atividades de origem industrial, doméstica, hospitalar, comercial, agrícola, de serviços e de varrição. Ficam incluídos nesta definição os lodos provenientes de sistemas de tratamento de água, aqueles gerados em equipamentos e instalações de controle de poluição, bem como determinados líquidos cujas particularidades tornem inviável o seu lançamento na rede pública de esgotos ou corpos de água, ou exijam para isso soluções técnicas e economicamente inviáveis em face à melhor tecnologia disponível.
\end{abstract}

Em outras palavras, resíduos sólidos são entendidos como tudo aquilo que é considerado como restos ou coisas sem valor. Vale lembrar, entretanto, que o que deixa de ter valor para uma parcela da sociedade pode ter valor para outras pessoas. Recentemente, milhões de pessoas têm garantido sua renda com a coleta de materiais recicláveis que antes iam para os lixões, terrenos baldios e aterros sanitários.

Para caracterizar o que pode ser coletado, reciclável ou reutilizável é necessário entender a origem dos resíduos sólidos. A bibliografia específica diferencia os resíduos sólidos em vários tipos, de acordo com sua origem. 
O primeiro tipo a ser destacado é o resíduo residencial/domiciliar que se origina da vida diária das famílias, como restos de alimentos, papéis, revistas, garrafas, embalagens em geral, entre outros. Vários desses materiais que são descartados pelas famílias podem ser destinados à coleta seletiva, à reciclagem ou ser reaproveitados.

Já os resíduos comerciais são aqueles originados de estabelecimentos de prestação de serviços e comerciais, como lojas, bancos, supermercados e vários outros estabelecimentos. Esse tipo de descarte também apresenta um grande potencial de materiais recicláveis, como papéis, papelão, embalagens, caixas de madeira, entre outros.

O resíduo público caracteriza-se por resíduos originados pela limpeza das vias públicas, limpeza de córregos, terrenos e de locais onde se realizam as feiras livres. Nesse caso, grande parte dos resíduos não é reciclável, já que se trata de material orgânico, como folhas. Existem, porém, exceções como, por exemplo, as caixas de madeira, de FVL e demais embalagens descartadas em locais de feiras livres.

No caso dos resíduos industriais, são gerados por atividades industriais, apresentando características e composições variadas, podendo conter fibras, borrachas, materiais cerâmicos e outros. De acordo com Tenório; Espinosa (2004), o manejo e destino desses resíduos são de responsabilidade da empresa geradora.

Já os resíduos dos serviços de saúde são aqueles produzidos em hospitais, farmácias, laboratórios, clínicas, consultórios e similares. Para os autores citados, esses resíduos dos serviços da saúde podem ser divididos em dois níveis: resíduos comuns, que são os restos de alimentos e papéis, e os resíduos sépticos, que são os restos de material cirúrgico ou de tratamento médico. Seu manejo deve ter atenção especial por representar riscos à saúde pública.

Os resíduos de portos, aeroportos, terminais rodoviários e ferroviários, que se originam basicamente de material de higiene e limpeza pessoal e restos de comida, podem transmitir doenças advindas de outras cidades, estados ou países. (IBAM, 2010).

Ainda há os resíduos agrícolas, que são caracterizados como restos das atividades agrícolas ou pecuárias. Nesse tipo, podemos incluir embalagens de adubos, ração, esterco animal, restos de colheita e também embalagens de agroquímicos. Por conterem 
alto grau de toxicidade, esses resíduos, assim como os industriais, também são de responsabilidade de seu gerador.

Outro tipo de resíduo sólido que é gerado em grandes volumes, especialmente, nas áreas urbanas, são os entulhos da construção civil, que correspondem a restos de obras, reformas ou demolições.

Existem, ainda, os resíduos volumosos, que não são removidos pela coleta rotineira, como embalagens grandes, equipamentos e móveis inutilizados, restos de podas de árvores, manutenção de áreas verdes e outros.

Precisamente não há dados exatos do número de toneladas de resíduos produzidas diariamente no mundo, mas se sabe que, cotidianamente, a sociedade gera volumes cada vez maiores. Estima-se que, no mundo, entre lixo domiciliar e comercial são produzidos 2 milhões de toneladas/dia. Isso equivale a aproximadamente 700 gramas por habitante de áreas urbanas. Só a população de Nova lorque, em decorrência do alto poder aquisitivo e do consumismo desenfreado, tem uma média bem superior a essa. Calcula-se que cada cidadão nova-iorquino gere 3 quilos por dia.

Dias (2002) compara a geração de resíduos sólidos per capita (quilos anual) pela população de algumas cidades do mundo. A população de Abidjan (Costa do Marfim) produz 200 quilos/ano; a de Quito (Equador), 281 quilos/ano; a de Bangkok (Tailândia), 321 quilos por ano; a de São Paulo (Brasil), 352 quilos/ano e a de Washington (Estados Unidos), 1.246 quilos por ano ${ }^{5}$.

Atualizando esses dados para o Brasil, um estudo recente elaborado pelo Senado Federal, juntamente com o Compromisso Empresarial para Reciclagem (CEMPRE) e a Associação Brasileira de Empresas de Limpeza Pública e Resíduos Especiais (ABRELPE), demonstrou que, em 2008, eram gerados, anualmente, 337 quilos, elevandose para 359,4 quilos por habitante em 2009. (SASSINE, 2010).

O desafio cada vez maior é dar um fim adequado a esse volume de resíduos sólidos que vem aumentando dia a dia.

O estudo citado aponta que, no ano de 2008, foram produzidos 52,93 milhões de toneladas; já em 2009, esse volume elevou-se para 57,01 milhões de toneladas. Com relação ao fim correto para todos esses resíduos, no ano de 2008, 55\% foram

\footnotetext{
${ }^{5}$ Os dados que Dias (2002) apresenta são referentes ao ano de 1997.
} 
adequadamente dispostos e, em 2009, esse percentual elevou-se para 57\%. (SASSINE, 2010).

Importa questionar: Até o presente momento, quem seria o responsável legal, no Brasil, pelos resíduos sólidos tidos como "comuns", aqueles que geramos em nossos lares e estabelecimentos comerciais, como embalagens, papel, papelão, restos de comida, entre outros?

A Constituição Federal, no Art. 30, incisos I, II e V, dispõe que compete aos municípios: legislar sobre assuntos de interesse local; suplementar a legislação estadual e federal no que couber; organizar e prestar, diretamente ou sob regime de concessão ou permissão, os serviços públicos de interesse local, incluído o transporte coletivo que tem caráter essencial. Diante disso, a Carta Magna deixa clara a responsabilidade e competência do município no que se refere aos serviços públicos locais, compreendidos nestes o correto gerenciamento dos resíduos por ele gerados.

A coleta normalmente é feita no sistema de porta em porta (de domicílios e estabelecimentos) por caminhões. De acordo com Sassine (2010), as prefeituras do Brasil gastam, em média, $\mathrm{R} \$ 9,27$ por habitante, em um mês, para coletar os resíduos sólidos.

Já Rocha (2007) vê, na Agenda 21, possíveis soluções para os resíduos sólidos, citando quatro programas que deverão estar interligados para melhor manejo dos resíduos sólidos: redução ao mínimo dos resíduos; maximização da reutilização e reciclagem; promoção da disposição e tratamento ambientalmente saudáveis dos resíduos, e, por fim, ampliação da cobertura dos serviços relacionados com os resíduos.

Considerados os em pontos discutidos acima, como o alto custo da coleta dos resíduos sólidos, ao modelo dos "3 Rs", que implicam mudanças no hábito da população, desde a produção, destinação e utilização até o descarte de resíduos sólidos.

De acordo com Vilhena; Silva (2010), "o Brasil gera, diariamente, cerca de 100 mil toneladas de lixo. Desse total, a maior parte - aproximadamente $60 \%$ - é constituída de material orgânico, isto é, restos de frutas, legumes, verduras e alimentos em geral". Parte do que sobra pode ser reciclada. Além disso, o processo de reciclagem contribui para a área ambiental e pode ajudar na conscientização sobre o valor daquilo que está sendo desperdiçado e descartado. 
Tenório; Espinosa (2004) afirmam que, no Brasil, a quantidade de programas de reciclagem de resíduos é ainda bastante inexpressiva, se comparada à demanda que existe em todos os municípios. Ainda assim, há materiais que são amplamente coletados e reciclados e isso se explica por se tratar de meio de sobrevivência de milhares de pessoas.

No artigo de Sassine (2010), os índices de reciclagem no Brasil estão assimconfiguradas: o papel de escritório recicla 43,7\%; plástico $21,2 \%$; latas de alumínio, 91,5\%; vidro 47\%; embalagens em polietileno tereftalato - conhecidos por "pet", 54,8\% e de embalagem longa vida, 26,6\%. Verifica-se que ainda há muito que crescer.

O texto de Calderoni (1997), escrito na década de 1990, já alertava a sociedade brasileira para o desperdício de bilhões de reais com a não reciclagem, ou seja, jogamos, no lixo, materiais que poderiam ser reciclados.

Atualizando esses dados a partir da informação das próprias indústrias, o potencial econômico do que poderia ser reciclado está na casa dos US\$ 8 bilhões, mas, infelizmente, ainda há uma quantidade elevada de materiais que poderiam ser recicláveis mas vão diretamente para os lixões e aterros sanitários, deixando, assim, de economizar energia, recursos naturais e de gerar empregos e renda. (CRESPO; COSTA, 2010).

\section{CONSIDERAÇÕES SOBRE LOGÍSTICA}

Ao reproduzir o conceito de economia de Samuelson (1970) citado no texto de Fontes (2010, p.1) verifica-se a necessidade de produção, distribuição e consumo: "Economia é a ciência que estuda a alocação de fatores de produção escassos entre diferentes alternativas de produção de bens e serviços, ao longo do tempo, para uma distribuição destes, no presente e futuro, entre a sociedade".

Não basta produzir um bem ou produto; é necessário que este chegue até o consumidor. Dessa forma, para uma empresa atuar na economia, torna-se fundamental a gestão eficaz das atividades logísticas, chamadas também de gerenciamento da cadeia de suprimentos. (Supply Chain Management). 
Logística pode ser definida como o processo de planejamento, implantação e domínio do fluxo eficiente e eficaz de produtos, serviços e das informações relativas, desde o ponto de origem até o ponto de consumo com o propósito de atender às exigências de seus clientes. Essa definição foi promulgada pelo Council of Logistics Management (CLM), uma organização de gestores logísticos, educadores e profissionais da área, criada em 1962.

Já Becco; Nunes (2010) afirmam que a logística pode ser entendida como o conjunto de todas as atividades de movimentação e armazenagem necessárias, de modo a facilitar o fluxo de produtos do ponto de aquisição da matéria-prima até o ponto de consumo final, como também dos fluxos de informação que colocam os produtos em movimento, obtendo níveis de serviço adequados aos clientes, a um custo razoável.

De forma sintetizada, a logística é a localização, o transporte e o estoque de materiais ou serviços, agregando valor a produtos e serviços essenciais para a satisfação do consumidor e, consequentemente, melhorando sua lucratividade.

Seu objetivo é colocar os produtos ou serviços certos no lugar certo, no momento certo e nas condições almejadas, proporcionando a melhor contribuição possível à empresa.

Antes de a logística se desenvolver, as comunidades só consumiam os produtos locais ou das proximidades. A partir dela, puderam ter acesso a maior variedade de produtos e serviços, pois o transporte facilitou a locomoção dos produtos comercializados a diferentes localidades. De acordo com Ballou (2005, p. 25), "as atividades logísticas são a ponte que faz a ligação entre locais de produção e mercados separados por tempo e distância".

Já Becco; Nunes (2010, p.04) citando Porter (1989), lembram que "[...] toda empresa é uma reunião de atividades que são executadas para projetar, produzir e comercializar, entregar e sustentar seu produto". Dessa forma, deve-se acompanhar o fluxo de mercadorias desde o ponto em que existem como matérias-primas até o ponto em que são descartadas, ou reaproveitadas, ou seja, a realização do processo de LR.

\section{LOGÍSTICA REVERSA}


Como já apresentado, os resíduos sólidos - sejam eles comerciais; industriais; domésticos; hospitalares - têm sido um grave problema ambiental, social e econômico para a sociedade atual. Leite (2003) traz o debate em torno desse problema afirmando que se tem se tornado cada vez mais presente e vem ganhando força junto às empresas, governo e sociedade, sendo de extrema importância, podendo afetar o equilíbrio ambiental.

Possíveis soluções para amenizá-lo são cada vez mais desejadas, uma vez que é praticamente impossível dar o fim adequado para todo resíduo que geramos diariamente. A política dos 3 R's tem sido o ponto de partida para todas as possíveis soluções. Partindo desse pressuposto, discute-se a LR.

Quando se fala somente em "logística", geralmente se tem a ideia de transporte e armazenagem de recursos, informações e equipamentos até chegar ao consumidor final. Existe, no entanto, o fluxo inverso, que procura levar os materiais do ponto de consumo ao ponto de origem. Intitula-se de "logística reversa", o reaproveitamento e reciclagem do material que seria descartado, que pode ser visto como uma possibilidade de reduzir os custos ou até aumentar o lucro de quem a pratica.

Mesmo sendo um conceito bem atual, a LR já era observada nas indústrias de bebidas, com o uso dos vasilhames que eram utilizados pelo consumidor e depois voltavam pra indústrias para serem reutilizados e voltarem novamente ao consumidor. Esse procedimento teve fim com a substituição dos vasilhames pelos descartáveis, mas, atualmente, esse processo vem sendo retomado.

Até há pouco anos, as empresas não se sentiam responsáveis pelos produtos que comercializavam após o seu consumo. A pressão de uma parcela da sociedade, a legislação ambiental mais severa, e até mesmo um maior grau de conscientização ambiental dos consumidores fizeram que empresas começassem a rever o destino que davam aos resíduos sólidos que geravam.

Um dos objetivos do empresário é atuar de maneira mais eficiente possível para minimizar custos. Assim, a LR pode ser vista como uma ferramenta para essa finalidade, pois, ao dar um novo destino ao material que seria descartado, a empresa, além de evitar 
o desperdício dos seus recursos, pode lucrar (ou mesmo, economizar) reutilizando ou vendendo esse material.

Outro ponto positivo é que o empresário pode aumentar seu comprometimento com o meio ambiente quando reduz a geração de lixo. Essa prática pode contribuir com a agregação de valor junto ao consumidor final.

Mesmo trazendo todos esses benefícios, muitas empresas não se interessam pela implantação da LR. Braga Júnior et al (2010), citando vários estudos, apontam alguns dos motivos para esse desinteresse. O primeiro deles é a falta de sistemas informatizados que permitam a integração de LR ao fluxo normal de distribuição. O segundo ponto é a dificuldade para medir o impacto dos retornos de produtos ou materiais, com o consequente desconhecimento da necessidade de controlá-lo. Há, ainda, o fato de que muitas empresas consideram que o fluxo reverso não representa receitas, mas custos e, como tal, não se configura como prioridade.

Já os fatores que motivam as empresas a adotar a LR são: questões ambientais como a legislação ambiental, que cada vez mais imputa à empresa a responsabilidade pelo ciclo de vida de seus produtos; os consumidores, que estão ficando cada vez mais exigentes quanto às políticas ambientais adotadas pela empresa; os benefícios econômicos obtidos com o retorno dos produtos ao processo de produção, evitando gastos com o correto descarte do lixo; a necessidade de redução de custos e até mesmo a concorrência, que força a empresa a buscar um diferencial perante os consumidores. (MUELLER, 2010).

Existem dois tipos de LR: a LR pós-consumo e a LR pós-venda. A LR pós-consumo visa à administração não somente da entrega do produto ao cliente, mas também do retorno, quando esse produto será direcionado para ser reutilizado ou descartado em um local seguro de forma ambientalmente correta. Por sua vez, a LR pós-venda cuida do retorno dos produtos dos consumidores aos fornecedores por razões comerciais, garantias oferecidas pelos fabricantes, erros no processamento de pedidos, desistência da compra ou defeito do produto.

Vale lembrar que, quando se utiliza a LR para o retorno de materiais do consumidor ao fabricante, a cadeia de suprimentos torna-se uma cadeia de suprimentos integral, pois o produto, além de percorrer a cadeia normal de suprimentos, passa também pelo 
descarte, recuperação e reaplicação, o que permite que o produto, depois do consumo retorne à cadeia de suprimentos. Importa esclarecer que, segundo Ballou (2005, p.28) "[...] abrange todas as atividades relacionadas com o fluxo e transformação de mercadorias desde o estágio da matéria-prima (extração) até o usuário final, bem como respectivos fluxos de informação".

\section{PERCURSO METODOLÓGICO}

Este estudo caracteriza-se como uma pesquisa descritiva, que tem por objetivo expor um determinado fenômeno (GIL, 2002): descreve-se aqui a LR em seis supermercados de cidades do interior paulista. A investigação foi desenvolvida em duas etapas: inicialmente, por meio de um levantamento e estudo bibliográfico e documental, posteriormente, por um conjunto de entrevistas realizadas com gerentes dos supermercados pesquisados.

Merriam (1998) ensina que uma proposta específica para a pesquisa documental e bibliográfica é apreender mais sobre determinada situação, pessoa ou determinado evento. A autora afirma que a pesquisa documental e bibliográfica pode ser utilizada, por exemplo, no estudo crítico sobre determinando evento, assim como a descrição de um programa ou evento, em que a intenção é esclarecer ou possibilitar uma contextualização da situação "atual". Nesse contexto, as fontes de pesquisa documental foram publicações (livros, artigos, notícias, entre outras), colhidas por meios eletrônicos e bibliotecas. É importante salientar que, além da revisão bibliográfica dos temas que tinham aderência com o escopo da LR, foi adotada neste estudo a técnica qualitativa de entrevista em profundidade, para atender ao objetivo de penetrar no universo dos atores envolvidos com o tema.

Fontana; Frey (2000) salientam que a entrevista em profundidade é uma modalidade de entrevista em que o pesquisador possui apenas um roteiro de temas que devem ser abordados, mas deixa a cargo dos pesquisados a construção das informações e dos sentidos. A intenção dessa entrevistas foi aprofundar e complementar as informações extraídas dos documentos e bibliografia. 
As visitas aos supermercados e as entrevistas foram realizadas na primeira quinzena do mês de julho de 2010. Informamos que a identidade dos supermercados e entrevistados serão preservadas.

\section{RESULTADOS DA PESQUISA}

A pesquisa foi realizada em seis supermercados (identificados como $A, B, C, D, E$ e F) das cidades paulistas de Castilho (16.446 habitantes), São José do Rio Preto (425.261 habitantes) e Votuporanga (84.521 habitantes) ${ }^{6}$.

O supermercado A está no ramo de varejo há 66 anos, contando com uma única loja, com aproximadamente $800 \mathrm{~m}^{2}$ de área e um depósito de $1.100 \mathrm{~m}^{2}$. Possui 7 checkouts (caixas) e atende, diariamente, em média 300 pessoas de todas as classes sociais da cidade. Conta com aproximadamente 60 colaboradores. A loja possui padaria, açougue e atualmente está em processo de implantação da rotisseria (venda de salgados e doces).

O supermercado B é uma filial de uma rede de 5 lojas que atua no mercado há 40 anos. Possui 15 check-outs, e localiza-se em um bairro populoso e antigo da cidade. Conta com 76 colaboradores. A loja possui padaria e açougue.

Já o supermercado C é uma das filiais da rede do supermercado acima citado, localizando-se também em um bairro populoso da cidade, tendo uma área de $1200 \mathrm{~m}^{2}$, com 22 check-outs. Atende aproximadamente 600 pessoas por dia, em média. Possui 113 colaboradores. A loja tem padaria, açougue e lanchonete, que comercializa apenas salgados.

O supermercado $D$ é uma das 8 unidades de uma rede que atua em 5 cidades do interior paulista. Está presente no mercado há 36 anos. Essa unidade conta com um quadro de 64 colaboradores. A área de venda e depósito da loja é de $1.200 \mathrm{~m}^{2}$. Possui 10

\footnotetext{
${ }^{6}$ Os dados referentes ao número de habitantes dos municípios são estimativas para o ano de 2010 da Fundação Sistema Estadual de Análise de Dados (Fundação SEADE) do Estado de São Paulo.
} 
check-outs e atende, em média, diariamente, 1.200 pessoas das classes A, B e C, mas a classe B é a predominante. Possui padaria, açougue e lanchonete.

O supermercado $\mathrm{E}$ pertence a uma rede de 3 lojas e está no ramo varejista há 23 anos. A loja conta com $6.950 \mathrm{~m}^{2}$, dos quais $3.800 \mathrm{~m}^{2}$ são de área de venda. Conta com 35 check-outs, que atendem, diariamente, 3.500 clientes das classes A, B e C. Possui 278 colaboradores. A loja conta com padaria, açougue, lanchonete (terceirizada) e rotisseria, que fornece, diariamente, refeições por kilo, marmitas e salgados.

O supermercado $\mathrm{F}$ é uma filial de uma rede de 4 lojas. A primeira loja da rede surgiu há 51 anos. A loja, depósito e estacionamento estão instalados em uma área de $5.000 \mathrm{~m}^{2}$, localizados em um bairro populoso da cidade. Conta com 22 check-outs, que atendem 3.000 clientes em média diariamente. Seu público predominante é de classe média. Conta com 170 colaboradores, e tem, na loja, padaria, açougue, lanchonete e restaurante onde oferecem comida por kilo, self service e salgados.

Todos os supermercados pesquisados informaram que geram basicamente os seguintes resíduos: plásticos (embalagens, fardos de refrigerantes, entre outros); papelão (caixas que acondicionam produtos que são comercializados nas lojas); caixas de madeira para transporte e acondicionamento de FVL; material orgânico, como FVL amassados, danificados, murchos e apodrecidos -; "pontas" de frios (queijos, salames, mortadelas e presuntos) ${ }^{7}$. Outra categoria de resíduos que são gerados nos supermercados são os produtos com o prazo de validade próximo do vencimento ou mesmo vencidos (o que os torna impróprios e proibidos para a comercialização).

Com exceção do supermercado A, o processo de LR já vem sendo praticado há vários anos, no entanto com intensidade menor. Isso se justifica em razão de ser um hábito comum e antigo a doação de frutas, legumes e verduras impróprias para a comercialização a pessoas que os utilizam para tratarem de animais, em especial porcos e galinhas.

A pesquisa de campo constatou que, no supermercado $F$, há um reaproveitamento parcial de FLV em sua lanchonete e restaurante. Já o supermercado $E$ utiliza de forma parcial as FLV, como, batatas, cenouras e tomates, em sua rotisseria. Já o supermercado

\footnotetext{
${ }^{7}$ Os frios normalmente são comercializados fatiados, porém as máquinas que executam essa ação não conseguem fatiá-las por inteiro, gerando assim, as conhecidas "pontas" de frios.
} 
D informou que, quando as FLV são retiradas das bancas, diariamente são doadas à Prefeitura Municipal, que reaproveita o que é possível e o restante é descartado.

Uma informação importante é que os supermercados $\mathrm{E}$ e $\mathrm{F}$ contam com o auxílio de uma nutricionista, que treina os colaboradores no manuseio, conservação e prevenção ao desperdício das FLV.

Há de se destacar que, nos demais supermercados, não há um profissional qualificado para treinar os colaboradores em relação ao não desperdício e à LR.

Já com relação às "pontas" de frios todos os supermercados as reaproveitam. O supermercado A reaproveita as "pontas" de frios como ingredientes de salgados que são comercializados em sua padaria. Outro destino é a comercialização, por um preço mais atraente, aos comerciantes que atuam no ramo de pizzaria e pastelaria da cidade.

Os demais supermercados utilizam as "pontas" de frios na produção de pizzas e salgados que são comercializados por eles.

Partindo para os resíduos sólidos, como embalagens de papelão e plásticas, todos os supermercados pesquisados afirmaram que realizam a separação e as vendem para empresas de reciclagem. Aqui há uma grande contribuição para a área ambiental, já que antes esses materiais eram descartados em aterros e lixões.

As caixas de madeira que são provenientes de FLV geralmente voltam para o fornecedor, entretanto há casos em que são utilizadas como lenha para a padaria própria, como é o caso do supermercado A. Já o supermercado $E$ doa as caixas para servirem como lenha para empresas da cidade.

Os produtos que estão vencidos ou próximos de sua data de vencimento, ou seja, impróprios para a comercialização, são retirados da área de venda e encaminhados ao depósito de trocas (alguns fornecedores responsabilizam-se pela troca). Há casos de fornecedores que não se responsabilizam pela devida troca e incentivam a baixa nos preços dos produtos. Em outros casos, os próprios supermercados optam pela baixa nos preços, em especial no caso de produtos de giro considerado rápido, como, por exemplo, cervejas, refrigerantes, entre outros. 
Outro dado que tem correlação com a área ambiental é o processo de recolhimento de óleo de cozinha ${ }^{8}$ usado, que é feito pelos supermercados D e F. Os supermercados funcionam como pontos de troca: os clientes trocam uma determinada quantidade de litros de óleo de cozinha usado por outros produtos, pré-estabelecidos pelos supermercados, como, por exemplo, um litro de óleo de soja ou dois litros de refrigerante. A preferência é que o óleo de cozinha usado seja acondicionado em garrafas pet, as quais também serão recicladas.

Um problema encontrado para a implantação da LR é a falta de espaço físico para acondicionar os resíduos sólidos como papelão e plásticos. Esse problema também ocorre no interior das lojas, que precisa de espaços para triagem/seleção de FLV, cozinha, lanchonete e restaurante. A questão de falta de tempo e treinamento dos colaboradores também é outro ponto fraco na implantação e otimização do processo de LR.

Durante a pesquisa somente o supermercado $D$ informou que a receita mensal das vendas dos materiais recicláveis (papelão e plástico) é de aproximadamente $R \$ 1.200,00$. Com relação à economia que é feita a partir do reaproveitamento das "pontas" de frios e partes das FLV, nenhum dos supermercados souber informar.

\section{CONCLUSÃO}

A LR, por não ser a "atividade fim" desse setor, não recebe a devida importância, pois a falsa visão de elevação dos custos inibe sua implantação.

A partir da pesquisa de campo realizada, conclui-se que não há custos financeiros adicionais para a implantação do processo de LR, tomando como base que nenhum dos supermercados pesquisados realizou novas contratações de colaboradores; apenas é necessária uma atenção extra por parte da totalidade da organização para realizar essa ação, que vem ao encontro da sustentabilidade ambiental.

\footnotetext{
${ }^{8}$ Esse tema merece um estudo mais aprofundado e detalhado, já que cada litro de óleo pode contaminar um milhão de litros de água.
} 
Constata-se que a LR, além de trazer uma receita extra, a partir da venda de recicláveis, evita o desperdício de produtos, que antes eram considerados lixo.

\section{REFERÊNCIAS}

BALLOU, R. H. Gerenciamento da cadeia de suprimentos: planejamento, organização e logística empresarial. 5aㅡ ed. Porto Alegre: Bookmann, 2005.

BECCO, José Eliseu; NUNES, Fernando Ribeiro de Melo. A logística dos supermercados periféricos estudo de caso em Fortaleza com aplicação do benchmarking In: XXIII ENCONTRO NACIONAL DE ENGENHARIA DE PRODUÇÃO, 2003, Ouro Preto, MG, Anais eletrônicos.... Ouro Preto: Associação Brasileira de Engenharia de Produção, 2003. <http://www.abepro.org.br/biblioteca/ENEGEP2003_TR0112_1389.pdf >. Acesso em: 21 jul. 2010.

BRAGA JÚNIOR, Sergio Silva; COSTA, Priscila Rezende; MERLO, Edgard Monforte. Logística reversa como alternativa de ganho para o varejo: um estudo de caso de um supermercado de médio porte. In: IX Simpósio de Administração da Produção, Logística e Operações Internacionais (SIMPOI), 2006, São Paulo, SP. Anais eletrônicos.... São Paulo: FGV-EAESP, 2006. Disponível em: <http://www.varejosustentavel.com.br/painel/dbarquivos/dbanexos/1_logsticareversacomo alternativadeganhoparaovarejop.pdf>. Acesso em: 22 jul. 2010.

CALDERONI, Sabetai. Os bilhões perdidos no lixo. São Paulo: Ed. Humanitas, 1997.

CRESPO, Samyra; COSTA, Silvano. Política para o lixo. Jornal Correio Brasiliense. Brasília, 07 jul 2010.

DIAS, Genabaldo Freire. Pegada ecológica e sustentabilidade humana. São Paulo: Gaia, 2002. 257 p.

FERREIRA, Aurélio Buarque Holanda. Mini Aurélio: 0 minidicionário da língua portuguesa. 4. ed. Rio de Janeiro: Nova Fronteira, 2001. 347 p.

FONTANA, A.; FREY, J. H. The interview: from structured questions to negotiated text. In: DENZIN, Norman. K.; LINCOLN, Yvona. S. (editors). The Handbook of qualitative research. 2nd ed. Thousand Oaks-California: Sage Publications, 2000.

FONTES, Rosa et al. Economia: um enfoque básico e simplificado. São Paulo: Atlas, 2010.

GIL, Antônio Carlos. Como elaborar projetos de pesquisa. 4. ed. São Paulo: Atlas, 2002. 
IBAM. INSTITUTO BRASILEIRO DE ADMINISTRAÇÃO MUNICIPAL. Cartilha de limpeza urbana. Disponível: <http://www.ibam.org.br/publique/media/Limpeza.PDF>. Acesso: 15 jul 2010.

LEITE, Paulo Roberto. Logística Reversa: meio ambiente e competitividade. São Paulo: Prentice Hall, 2003.

MERRIAM, Sharan. B. Qualitative research and case study applications in education. Rev. and expanded. 1st ed. San Francisco: Jossey-Bass, 1988.

MUELLER, Carla Fernanda. Logística reversa. meio ambiente e produtividade. Disponível em: <http://www.gelog.ufsc.br>. Acesso em: 22 jul. 2010.

OLIVEIRA, Edenis César; RIZZO, Marçal Rogério. O lixo como questão estratégica Disponível em: <http://. www.ambientebrasil.com.br. Acesso em: 19 jul. 2010.

RIZZO, Marçal Rogério; SANTOS, Márcio Gomes. Repensai a geração de lixo e dejetos. Jornal A Tribuna. Jales, 27 jan 2008.

SASSINE, Vinicius. Passo atrás na coleta seletiva. Jornal Correio Brasiliense. Brasília, 12 jul 2010.

SILVA, Jorge Xavier; ZAIDAN, Ricardo Tavares. Geoprocessamento e análise ambiental. São Paulo: Bertrand Brasil. 2007. 368 p.

TENÓRIO, Jorge Alberto. Soares.; ESPINOSA, Denise Crocce Romano. Controle Ambiental de Resíduos. In: PHILIPPI Jr, Arlindo.; ROMERO, Marcelo Andrade.; BRUNA, Gilda Collet. Curso de Gestão Ambiental. Barueri, SP: Manole, 2004. p. 155-211.

VILHENA, Marilene de Oliveira; SILVA, Maclovia Corrêa. Aproveitamento integral de alimentos orgânicos: arte culinária verde. In: II JORNADA NACIONAL DE PRODUÇÃO CIENTIFICA EM EDUCAÇÃO PROFISSIONAL E TECNOLÓGICA, 2007, São Luis, MA, Anais eletrônicos.... São Luis: 2007. Disponível em: <http://www.pessoal.utfpr.edu.br/macloviasilva/arquivos/arte_culinaria_verde.pdf $>$. Acesso em: 22 jul. 2010. 